\title{
Habitação de interesse social em Porto Alegre: um estudo retrospectivo das políticas municipais cotejado com a implementação do Programa Minha Casa Minha Vida
}

\author{
Social housing in Porto Alegre: a retrospective studying about the municipal public \\ policies collated with the implementation of Minha Casa Minha Vida Program.
}

\author{
Marcos Pereira Diligenti* \\ Idilia Fernandes ** \\ Tiago de Campos***
}

\begin{abstract}
Resumo:
As políticas públicas na área da Habitação de Interesse Social no Brasil, foram significativamente intensificadas com a implementação do Programa Minha Casa Minha Vida (MCMV) em nível federal, a partir de março de 2009. Os resultados quantitativos na produção de moradias foram substanciais, no entanto, faz-se necessária uma análise crítica do Programa no que diz respeito à produção de cidades. $O$ objetivo deste artigo é estabelecer um cotejamento das políticas até então adotadas, com foco na Cidade de Porto Alegre, para verificar se a posterior centralização dos recursos federais foi o caminho mais acertado para a desejável promoção de cidades inclusivas, participativas e democráticas.
\end{abstract}

Palavras Chave: Programa MCMV. Políticas públicas municipais em Porto Alegre. Cidades inclusivas. Direitos humanos. COMATHAB.

\begin{abstract}
:
The Public Policies in Social Housing in Brazil had been significantly increased with the implementation of My House My Life (MVMC) Program in a federal level, since March 2009. The quantitative results in the production of dwellings were substantial however, its necessary a critical Analysis about the Program with regard to city production and planning. The objective of this article is to establish a comparison with policies until then adopted, focusing in Porto Alegre city, to verify if the subsequent centralization of the resources in the federal level had been the best way to the desired promotion of most inclusive, participative and democratic Cities
\end{abstract}

Keywords: Program MCMV. Municipal public policies in Porto Alegre. Inclusive cities. Human rights. COMATHAB.

\footnotetext{
* Pós-Doutorado pela Pontifícia Universidad Católica de Chile/Santiago em Viviendas Sociales. Pós-Doutorado pelo Instituto Superior Técnico de Lisboa em Arquitetura e Urbanismo na área da Habitação Social. Doutorado em Educação pela Universidade Federal do Rio Grande do Sul. Docente da Faculdade de Arquitetura e Urbanismo e Programa de Pós-Graduação em Serviço Social da Escola de Humanidades Pontifícia Universidade Católica do Rio Grande do Sul. E-mail: mdilig@pucrs.br

** Doutora em Serviço Social pela Pontifícia Universidade Católica do Rio Grande do Sul. Professora visitante da Universidade Luterana do Brasil. Professora do Programa de Pós-Graduação em Serviço Social da Escola de Humanidades - Pontifícia Universidade Católica do Rio Grande do Sul. E-mail: idilia.fernandes@pucrs.br

*** Graduando em Arquitetura e Urbanismo na Pontifícia Universidade Católica do Rio Grande do Sul, PUCRS, Brasil. Bolsista BPA/PUCRS. E-mail: tiagodecampos@gmail.com
} 


\title{
Habitação de Interesse Social e as Ações Desenvolvidos pela Prefeitura Municipal de Porto Alegre
}

\begin{abstract}
Estamos, portanto, diante de uma 'guerra dos lugares' ou de uma guerra 'pelos lugares". Nesta guerra, o que está em jogo são processos coletivos de construção de 'contraespaços': movimentos de resistência à redução dos lugares a loci de extração de renda e, simultaneamente, movimentos de experimentação de alternativas e futuros possíveis.'
\end{abstract}

Raquel Rolnik

A Habitação de Interesse Social é um setor de problemas humanos mais relacionado a cidade, em suma é a moradia para famílias e pessoas de baixa renda. A Habitação sempre foi um problema urbano desde que a humanidade passou a estabelecer-se em cidades. Com o crescimento da civilização humana, as cidades foram aumentando e os problemas relacionado a ela, principalmente com a adoção do sistema capitalista onde é preciso ter para habitar (BONDUKI, 2004). Desde que começou a ser discutido, nos primórdios da revolução industrial, onde o problema de habitação tomou proporções quantitativas devido ao êxodo rural na Europa industrial do séc. XIX.

Todavia, a discussão de habitação nunca obedeceu às reais necessidades dos que mais precisavam dela, os pobres e desabrigados. Daí surge, a necessidade da participação social no processo de decisão de onde e como morar. A discussão, gestão e tomada de decisões do tema pela sociedade é primordial para que o problema seja realmente resolvido. Ao longo do tempo muito já foi feito, todavia, o problema só aumenta. Uma das causas desse aumento desenfreado do déficit habitacional tóxico para as sociedades humanas é, justamente, a não participação da sociedade civil interessada no tema.

O problema da Habitação de Interesse Social no País é um desafio que envolve diversas áreas do conhecimento e, fundamentalmente, a forma de gestão pública adotada nos programas habitacionais. Alguns municípios, estados e até mesmo a federação, desenvolveram projetos e programas que visavam à promoção da Habitação de Interesse Social ao longo do tempo.

Porto Alegre é um desses municípios, que desde o ano de 1955 com a criação do DMCP - Departamento Municipal da Casa Popular, visou a construção e a desapropriação de grandes extensões de terra para a habitação popular. Todavia com o Golpe Militar de 1964 a autarquia municipal perdeu poder e recursos para continuar desenvolvendo suas ações. $A$ partir desse momento, por meio da lei 2.092 de 30 de novembro de 1965, o DMCP foi reestruturado e transformado no DMHAB - Departamento Municipal de Habitação Social, 
que visava à construção de casas populares com recursos do então Programa Federal de Habitação o BNH - Banco Nacional da Habitação. Apesar de seguir as regras do governo central, esse órgão passou a receber recursos do BNH somente no ano de 1970 (antes disso obtinha os recursos do Fundo Municipal de Habitação²).

Desde que o DEMHAB iniciou suas atividades com investimentos federais oriundos do BNH, em 1970, até o ano de 1986, a autarquia municipal implementou na cidade os programas do Governo Federal: PROGENTE (1975), PLANHAP - Plano Nacional de Habitação Popular (1976), PROLIFURB - Programa de Financiamento de Lotes Urbanizados (1979), FICAM - Programa de Construção, Conclusão, Ampliação e Melhoria da Habitação de Interesse Social (1979) e o PROMORAR - Programa de Erradicação de Sub moradias (1980). Entre os anos de 1965 e 1988 foram entregues 10.639 unidades habitacionais no município de Porto Alegre (DMHAB, CHIS, 2014, p. 92).

Após o fim do Período Militar e a extinção do BNH, considerando-se que o programa não atingiu os seus propósitos iniciais que eram de atender as camadas menos favorecidas da população (quando de sua extinção, verificou-se que aproximadamente $70 \%$ dos contratos firmados sob esse instrumento financeiro eram voltados para as classes média e média alta), o Governo Federal não propôs nenhum programa substituto no sentido de atender à demanda de Habitação de Interesse Social. Entretanto, em Porto Alegre, com a institucionalização do Orçamento Participativo, as questões relacionadas à habitação passaram a se inscrever de forma contundente na agenda municipal. O Orçamento Participativo, que a partir de 1989, subverteu a lógica de uma democracia representativa, ao trazer para a esfera decisória a possibilidade deliberativa direta das comunidades na escolha dos investimentos públicos da cidade, representou um marco no sentido de intensificar a participação popular em todas as esferas de decisões e particularmente no caso habitacional, nas possibilidades de onde e como morar (FEDOZZI, 1997).

Dessa forma, com a falta de programas do Governo Federal para o tema, o DEMHAB voltou-se para a criação de novos programas e projetos na cidade, todos financiados pelo Fundo Municipal de Habitação e guiados pela participação popular. Dentre esses projetos destacou-se pela participação popular e vinculação com OP, o Programa de Incentivo às Cooperativas Habitacionais, instituído no ano de 1990. A efetividade dos resultados obtidos por esse programa subsidiou a decisão de, em 1993, implementar uma equipe exclusiva para

\footnotetext{
${ }^{2}$ Fundo financeiro municipal que recebe aportes das taxas e pagamentos oriundos de aprovação de projetos, compra de índices construtivos e outros recursos do município de Porto Alegre.
} 
tratar desse assunto no DEMHAB. Também em 1990, para suprir os problemas advindos da falta de regularização fundiária, a Secretaria de Planejamento Municipal criou o Programa de Regularização Fundiária - PRF que a partir de 1993 passou a ser exclusivamente competência do DEMHAB, visto a sua natureza urbanística e não apenas jurídica.

O Programa de Cooperativismo Habitacional Autogestionário, induziu à “organização de grupos humanos em cooperativas destinadas à aquisição de terrenos, formação de poupança, produção e licenciamento de projetos, orientação técnica e intermediação" (DEMHAB, 2000, p. 39). Cerca de 7 mil famílias foram beneficiadas organizadas em 68 cooperativas.

No que concerne ao Projeto Integrado Entrada na Cidade (PIEC), o objetivo do programa foram ações voltadas à habitação e ao desenvolvimento urbano, socioeconômico e ambiental da Região Humaitá-Navegantes. No entanto, foi apenas em 2005 que o Programa recebeu impulso para a sua criação. Esse projeto foi executado através de cinco subprogramas, entre eles o Projeto de Habitação de Interesse Social do Município de Porto Alegre. Cerca de 3.775 famílias foram contempladas com um investimento de $\mathrm{R} \$ 71,4$ milhões. Foram construídas 3.061 casas e 714 lotes urbanizados (PMPA, 2012).

Figura 1 - Esquema com as cinco ações do PIEC

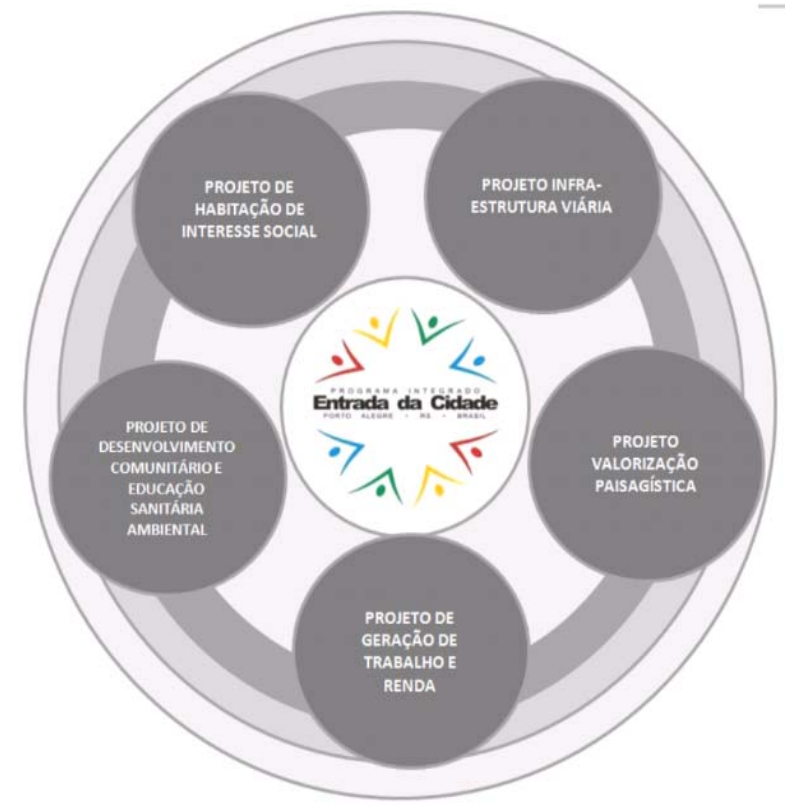

Fonte: PMPA/PMHIS (2007).

Outro programa municipal desse período consistiu no Programa de Reassentamento, que se caracterizou pela produção de empreendimentos dotados de infraestrutura básica e solução habitacional para as famílias cujos domicílios encontram-se 
em áreas impróprias para moradia. Oportunizou ao acesso às políticas públicas na implementação de serviços e equipamentos comunitários. Atuou como suporte ao Programa de Regularização Fundiária, para os casos em que não é possível manter as moradias nos locais originais. Além disso, de 1997 a 2000, foram beneficiadas cerca de 4 mil famílias (DEMHAB, 2000, p. 20). As tipologias utilizadas pelo Programa foram a casa térrea e o sobrado, além disso, a partir de 2001, passou a incluir projetos para portadores de necessidades especiais, garantindo assim, acessibilidade às novas moradias. Entre as ações do Programa, destacam-se, a Vila Chocolatão, Vila Nazaré e Vila Dique.

Ainda no sentido de atender à demanda de direito à propriedade, a Prefeitura Municipal instituiu o Programa de Regularização Fundiária que promoveu: o título do terreno, acesso ao saneamento, pavimentação, iluminação pública, rede elétrica e a todos os serviços públicos da cidade (DEMHAB, 2000, p. 08), e a construção de pequenos conjuntos habitacionais nas áreas já ocupadas pela população beneficiada. De 1997 a 2000, concomitantemente ao Programa de Reassentamento, foram atendidas cerca de 5 mil famílias em diversas zonas da cidade. Destaca-se que, apesar de ter sido instituído em 1990 pela Secretaria do Planejamento Municipal, apenas em 1993 ele passou a ser desenvolvido exclusivamente pelo DEMHAB (PMHIS, 2007).

A seguir será apresentado um esquema com as ações concernentes ao PRF:

Figura 2 - Fluxograma com as ações do PRF

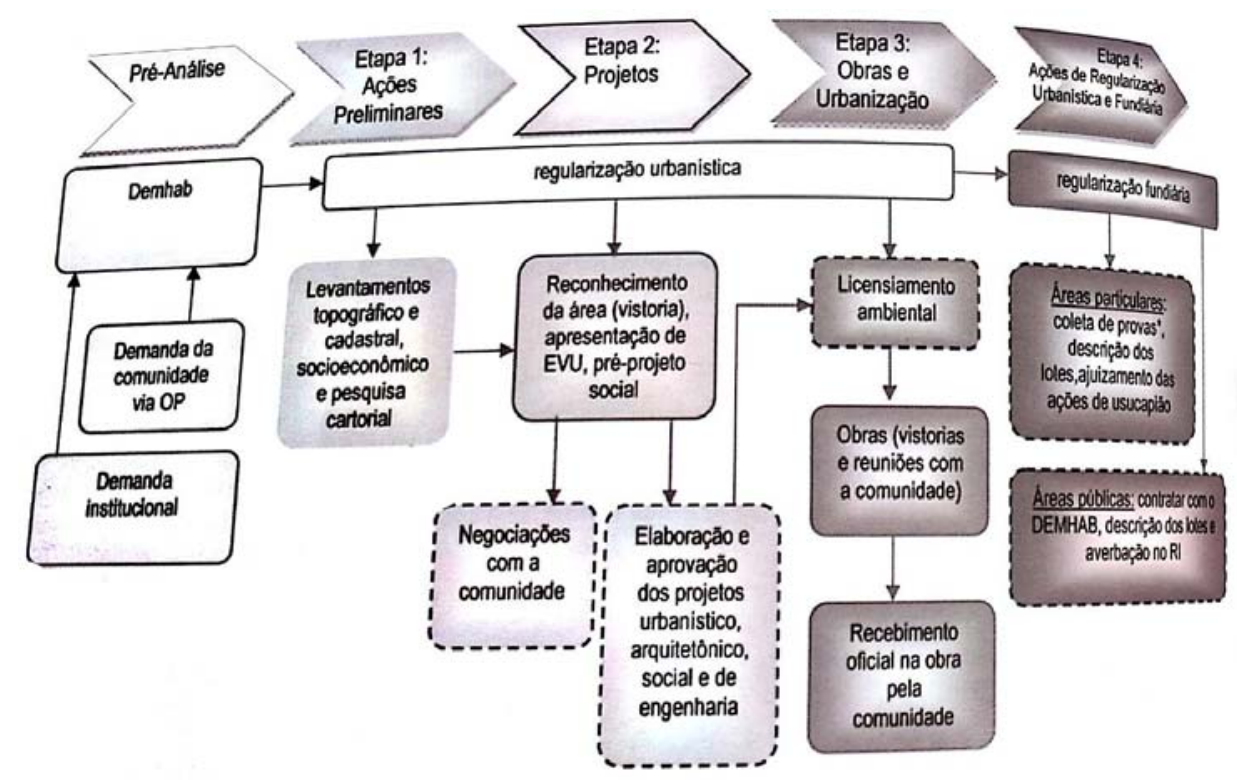

Fonte: DEMHAB e CHIS (2014). 
Apesar das medidas adotadas e da moradia ter sido definida como direito social no Art. $6^{\circ}$ do Capítulo II dos Direitos Sociais da Constituição da República Federativa do Brasil de 1988 (CONSTITUIÇÃO DA REPÚBLICA FEDERATIVA DO BRASIL, 1988), Porto Alegre possui, segundo dados do Censo do IBGE de 2010, 56.024 unidades habitacionais em "aglomerados subnormais", abrigando 192.804 pessoas em 108 assentamentos. Porém, deve-se ressaltar que em função do senso do IBGE limitar suas pesquisas de acordo com a dimensão das unidades habitacionais, ao se adotar informações disponibilizadas pelo DEMHAB, cuja metodologia emprega de forma mais ampla o espectro investigado, observa-se um aumento dos números constatados, segundo esse órgão municipal. Há 479 núcleos e vilas irregulares em Porto Alegre, onde estão localizados 74.522 domicílios. Portanto, a partir desses dados, torna-se inquestionável a existência de um grave problema de carência habitacional na cidade de Porto Alegre, a despeito das medidas adotadas em nível municipal e federal.

Outras iniciativas de participação popular no que se refere às demandas habitacionais, foram criadas nesse período no município de Porto Alegre, um exemplo relevante de efetividade desse fluxo participativo observou-se com a criação do COMATHAB - Conselho Municipal de Acesso à Terra e Habitação em 1995 através da lei n 337, que em seu Art. $6^{\circ}$ prevê:

Art. $6^{\circ}$ - Ao Conselho Municipal de acesso à Terra e Habitação compete:

I - Propor, deliberar e fiscalizar diretrizes, planos e programas de Política Habitacional de Interesse Social do Município;

II - Propor e participar da deliberação, junto ao processo de elaboração do Orçamento Municipal, sobre execução de projetos e programas de urbanização, construção de moradias e de regularização fundiária em áreas irregulares, nos termos do $\S 1^{\circ}$, do art. 116 da lei Orgânica do Município de Porto Alegre;

III - Propor o plano de aplicação e fiscalizar o gerenciamento do Banco de Terras;

IV - Apreciar as propostas e projetos de intervenção do Governo Municipal relativas às ocupações e assentamentos de Interesse Social;

V - Propor os planos de aplicação dos recursos do Fundo Municipal de Desenvolvimento - FMD de que trata o art. 10 da Lei Complementar 315, de 10 de janeiro de 1994, bem como encaminhá-los ao processo de elaboração do orçamento para apreciação e deliberação;

VI - Apreciar as formas de apoio às entidades e cooperativas habitacionais cuja população seja de baixa renda, bem como solicitações de melhorias habitacionais em autoconstrução ou ajuda mútua de moradias populares;

VII - Propor ao órgão competente a criação de Áreas Especiais de Interesse Social AEIS;

VIII - Propor convênios destinados à execução dos projetos habitacionais, urbanização e regularização fundiária;

IX - Constituir Grupos Técnicos ou Comissões Especiais e Câmaras, quando julgar necessário, para o desempenho de suas funções;

$X$ - Exercer a fiscalização da administração financeira e contábil do FMD, podendo a qualquer momento, na forma do Regimento Interno, realizar perícias e verificações do caixa, bem como solicitar informações acerca de operações financeiras, licitações, convênios, contratos, fixação de preços públicos, desapropriações, alienações e permutas; 
$X I$ - Estabelecer relações com órgãos, conselhos e fóruns municipais afetos à elaboração do Orçamento Municipal e à definição da Política Urbana do Município. $\S 1^{\circ}$ - Mediante deliberação por maioria absoluta, o Conselho de Acesso à Terra e Habitação, bem como qualquer de seus conselheiros, terá acesso ao Cadastro do Banco de Terras do Município

$\S 2^{\circ}$ - O conselho poderá solicitar informações, bem como requerer perícias e verificações da administração financeira e contábil do DEMHAB.

No ano de 2001, após a realização das Conferências Municipais de Habitação para avaliação dos programas habitacionais da cidade de Porto Alegre, foram definidas diversas ações no sentido de qualificar esse processo. Destaca-se entre elas a criação do loteamento Vila Tecnológica, na região do bairro Humaitá onde foram implantadas novas técnicas construtivas para a habitação popular, visando à qualificação das edificações.

Nos anos seguintes, foram firmadas novas parcerias para financiar projetos habitacionais, o HBB-BID ${ }^{3}$ e o FONPLATA ${ }^{4}$. Com o apoio desses bancos foi possível a ampliação do PIEC - Programa Integrado Entrada da Cidade e a criação de um novo conceito em programa social que visava à integração das diferentes políticas sociais do município (PMPA, 2002).

No ano de 2007 por exigência do Governo Federal e para que o município de Porto Alegre continuasse recebendo repasses para Habitação de Interesse Social (PMHIS, 2007), o DEMHAB como autarquia responsável pelo tema da Habitação Social foi encarregado da criação do PMHIS- Plano Municipal de Habitação de Interesse Social, "no qual são definidas diretrizes, objetivos, metas e estratégias de ação na superação do "déficit" habitacional de Porto Alegre, no que tange a população de baixa renda" (PHMIS, 2007).

Com a implementação pelo Governo Federal no ano de 2009 do programa Minha Casa Minha Vida, observou-se, de forma geral, um refluxo nas políticas habitacionais municipais anteriormente elencadas, já que os investimentos para essas camadas populacionais passaram a concentrar-se na esfera do programa do Governo Federal. Porto Alegre, como a maior parte dos municípios brasileiros, adotou essa nova forma de financiamento/política pública como prioritária na produção de Habitação de Interesse Social (ALFONSIN, 2013).

3 HBB-BID - Programa Habitar Brasil/BID - Programa de Habitação no Brasil com fundos do Banco Interamericano de Desenvolvimento e do Governo Federal, através do Ministério das Cidades.

4 FONPLATA - Fondo Financiero para el Desarrollo de la Cuenca del Plata/Fundo Financeiro para o Desenvolvimento da Bacia do Prata. 
Como forma de resumir o desenvolvimento das políticas habitacionais, será apresentado uma linha cronológica ilustrativa com as principais ações elencadas na presente proposta de investigação.

Figura 3 - Esquema com o histórico das políticas habitacionais em Porto Alegre

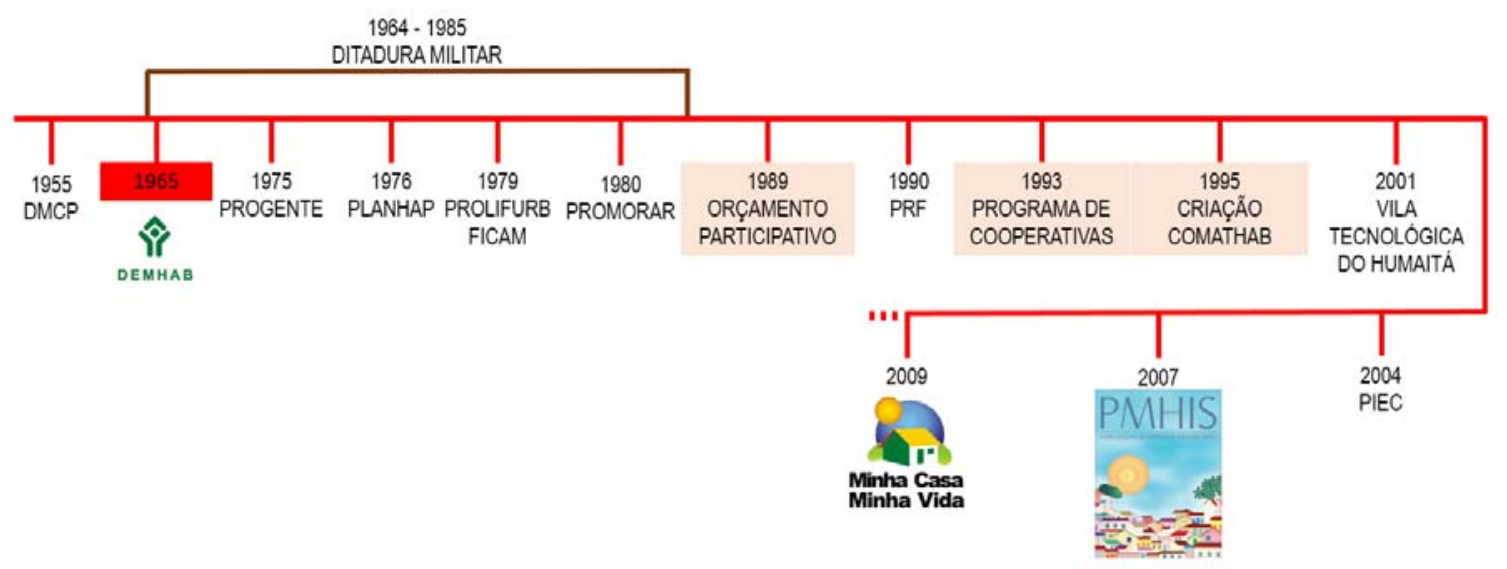

Fonte: Acervo dos autores.

Ao analisar o processo pelo qual as políticas públicas habitacionais em Porto Alegre passaram, desde a criação do DMCP - Departamento Municipal da Casa Popular em 1955, até a implementação do Orçamento Participativo, culminando com o advento do Programa Minha Casa Minha Vida, verificou-se a insuficiência desses instrumentos governamentais no sentido do atendimento satisfatório das demandas habitacionais na cidade de Porto Alegre. A relevância do estudo aqui proposto consistiu em, a partir de uma análise crítica do panorama histórico investigado, propor alternativas de superação que contemplem com eficácia as necessidades habitacionais junto às classes menos favorecidas economicamente, com foco de estudo realizado na cidade de Porto Alegre.

Nesse sentido, considerando-se à priorização do programa MCMV como instrumento de política habitacional dos municípios e no caso particular de Porto Alegre, foco do estudo aqui proposto, essa pesquisa procurou buscar com as positividades e negatividades, algumas conclusões e perspectivas de qualificação das gestões governamentais ligadas a esse tema de emergência ímpar nas cidades brasileiras, que consiste na Habitação de Interesse Social e sua relação com o modo de viver a cidade. 


\section{Metodologia Aplicada na Busca de Dados}

A presente proposta baseou-se em analisar dados, valores e técnicas utilizadas pelos órgãos municipais da cidade de Porto Alegre. Relatórios, publicações e revistas também foram utilizados nesta pesquisa, com o intuito de reunir informações relativas à participação popular e metodologia adotada no município de Porto Alegre no que diz respeito às demandas habitacionais.

Os dados foram colhidos junto aos órgãos municipais, à produção bibliográfica da área, boletins e relatórios; foram realizadas visitas "in loco" para a verificação das condições atuais das Habitações de Interesse Social, acervos das respectivas plantas utilizadas, bem como a investigação junto aos movimentos sociais que advogam em favor do tema de habitação social. Foram consultados, instrumentos jurídicos no que tange ao direito urbanístico na cidade de Porto Alegre no período compreendido nessa investigação. Em posse desse material coletado procedeu-se a análise, segundo o método da hermenêutica dialética no conceito de Minayo, onde salientou-se que, os aparentes paradoxos, ao invés de inibirem, estimulam à compreensão dos fenômenos.

Enquanto a hermenêutica penetra no seu tempo e através da compreensão procura atingir o sentido do texto, a crítica dialética se dirige contra o seu tempo. Ela enfatiza a diferença, o contraste, o dissenso e a ruptura de sentido. A hermenêutica destaca a mediação, o acordo e a unidade de sentido. Assim a hermenêutica e a dialética apresentamse como momentos necessários na produção da racionalidade. (MINAYO,2000, p.227)

A análise de dados teve nesse sentido uma perspectiva complementar de pesquisa que complementou aspectos quantitativos à aspectos qualitativos.

\section{Minha casa, Minha Vida... e a Cidade?}

Reavaliou-se nessa investigação os processos de projeto implementação gestão participação popular relacionados aos Programas de Habitação de Interesse Social, por intermédio da contribuição dos aportes históricos e da constatação nas ocupações e movimentos pela habitação, que teve-se a oportunidade de participar e acompanhar no período, com o objetivo de qualificar sua efetividade social, econômica e ambiental, como forma de instrumento de gestão para a inclusão social por meio do acesso à cidade de Porto Alegre. 
Analisou-se criticamente a substituição, quase absoluta, dos programas municipais pelo programa Minha Casa Minha Vida, de nível federal como forma de solução dos problemas habitacionais.

Importa saber que o objetivo dessa investigação foi realizar um cotejamento das políticas habitacionais adotadas na cidade de Porto Alegre com as políticas introduzidas a partir da implementação do Programa Minha Casa Minha Vida. Procurou-se identificar para além de uma análise crítica, um importante foco de pesquisa que consistia na concentração dos investimentos em nível federal (MCMV) e, com isso, uma possível causa para o esvaziamento das políticas locais em função desta priorização.

Para tanto, pretendeu-se também reunir dados quantitativos dos números de unidades entregues, bem como a qualidades dessas unidades antes e depois da entrada do Programa Minha Casa Minha Vida nas ações do município de Porto Alegre, para ter-se um perfil do impacto que o atual programa de habitação do governo federal teve em todos os aspectos que envolvem o processo de Habitação Social na Cidade.

A partir dessas análises, buscou-se o desenvolvimento de uma alternativa concreta de gestão participativa que atendesse satisfatoriamente às necessidades relacionadas com a moradia, e que estimulasse o conceito de uma cidade inclusiva com o combate à segregação socioespacial observada nos dias atuais e estabelecesse um contraponto à verificada lógica mercantilista adotada no urbanismo nas cidades contemporâneas.

As metas aqui estipuladas foram alcançadas na formação de uma rede analítica que abrangeu desde os dispositivos de participação popular nas decisões de como e onde foram feitas as habitações, até mesmo na análise das técnicas utilizadas em cada período que foi estudado. Para tanto, se fez fundamental a análise dos processos de regularização fundiária adotadas pelo município de Porto Alegre, cotejadas ao Programa Minha Casa Minha Vida.

A partir dessa investigação buscou-se a proposição de método alternativo de participação e gestão popular que atenda satisfatoriamente com a construção de Habitação de Interesse Social, utilizando-se de uma análise crítica dos programas e sistemas já existentes nas esferas municipal, estadual ou federal.

\section{A Financeirização do Território}

O resultado desta investigação mostrou que apesar dos esforços do DEMHAB em ampliar a participação popular nas decisões de onde e como morar, dos avanços em relação 
ao Orçamento Participativo, da Criação do setor das Cooperativas de Habitação e Trabalho e a instituição do COMATHAB o problema da Habitação de Interesse Social em Porto Alegre aumentou, junto do aumento populacional que a capital do Rio Grande do Sul passou, movimento este constatado em todo o Brasil.

Quando indagou-se o porquê deste processo intensificar-se quando o DEMHAB tem, em primeira vista, três dispositivos de certa forma eficazes no combate ao problema de habitação encontrou-se a sua raiz: o processo de financeirização que a produção de cidade tem sofrido nas últimas décadas em decorrência do sistema prioritariamente mercadológico.

Os fundos que o DEMHAB utilizava para a realização dos projetos e programas próprios antes do PMCMV vinham principalmente do Fundo Municipal de Habitação e da parceria com Bancos Multilaterais como o BID e o FONPLATA, instituições financeiras que visam ao lucro para a sua manutenção e expansão. Ao tomar empréstimos nessas instituições financeiras internacionais, o DEMHAB, comprometeu-se com muitas coisas tais como: à adequação a algumas regras para a sua implementação. A mais comprometedora de todas foi a abertura do capital imobiliário para trabalhar junto ao poder público na exploração da cidade.

Concluiu-se parcialmente, depois da análise das informações apresentadas que o DEMHAB fica refém de interesses particulares em contratos e negócios firmados com tais instituições. Contratos esses que não são apresentados aos maiores interessados, que são as pessoas de mais baixa renda que sofrem com a falta de habitação e saneamento básico. Um exemplo concreto desse processo é o PIEC - Programa Integrado de Entrada da Cidade, programa esse que fez várias obras de saneamento básico e equipamentos públicos em uma área intitulada $4^{\circ}$ distrito, situado na região norte da cidade no acesso principal à capital. Essa região que no passado abrigava as grandes indústrias do Estado e que após a crise dos anos 60, que sofreram as capitais brasileiras verificou-se uma significativa migração para a região metropolitana, deixando o $4^{\circ}$ distrito abandonado e que aos poucos foi sendo ocupado por pessoas sem habitação. Área que foi esquecida e abandonada tanto pelo poder público quanto pelo poder privado, agora ressurge como uma das áreas mais valorizadas da cidade, estranhamente logo após as obras financiadas com dinheiro público. Para mais detalhes ver projeto consorciado do $4^{\circ}$ Distrito.

O período de análise das ações do DEMHAB compreende os anos de 1965, data da sua criação até o ano de 2015, vasto espaço de tempo que compreende grandes mudanças na maneira que a sociedade se comporta e vive. O tema de habitação é um dos setores que 
pouco se desenvolveu durante esse período, porém o mercado do capital aumentou e ficou cada vez mais forte e presente em todos os setores da vida urbana.

A adoção do modelo capitalista de mercado, e a habitação como supracitado, também foi impactada com essa perspectiva. Quando da análise dos dados obtidos ao longo da investigação esperou-se encontrar ações mais assertivas do Departamento no que tange à participação social e a melhoria do problema da habitação no município de Porto Alegre, todavia encontrou-se programas já configurados para atender aos interesses da exploração imobiliária (ROLNIK, 2015).

Até mesmo o COMATHAB e o Orçamento Participativo, que fizeram a participação popular emergir na pasta de habitação em Porto Alegre, foram ao longo do tempo, sucateados e perdendo força e, até mesmo, ficando viciados e comprometidos com o mercado imobiliário

\section{COMATHAB E FMHIS - Leis para o Protagonismo da População}

Como já citado anteriormente com o final do período de Ditadura Civil Militar no Brasil, os movimentos sociais começaram a se articular de forma mais intensa no que diz respeito aos seus direitos, propiciando à criação de modelos de gestão mais participativa, como por exemplo, o Orçamento Participativo - OP, também já mencionado nesta investigação. Esses modelos mais democráticos de participação, avaliação e gestão pública representaram naquele momento, um ganho significativo, depois de anos de repressão e distanciamento da população nas decisões do poder público.

Apesar de todos esses organismos serem criados e implantados, inclusive com o acréscimo da criação de fundos depositários, nas esferas municipais, estaduais e federais, nenhum deles concretamente, na atualidade, exercem o papel para o qual foram inicialmente planejados. Quando é mencionado o círculo vicioso que alguns instrumentos de participação pública entraram, pode-se citar o OP que, inicialmente propunha-se discutir abertamente com a população o orçamento total da prefeitura, no entanto, hoje restringese a um pequeno montante financeiro, a ser dividido entre eixos de interesse para 17 regiões da capital gaúcha.

Atualmente verifica-se que no Orçamento Participativo são postos em pauta projetos previamente formatados para que empresas previamente escolhidas (por licitação 
ou carta convite) executem obras de calçamento, saneamento básico e construção de unidades habitacionais (neste caso por meio do Programa Minha Casa Minha Vida).

Infere-se da pesquisa realizada que, instrumentos genuinamente participativos quando da sua implementação inicial acabaram por ser degenerados devido à centralização dos financiamentos em nível federal e a manipulação de setores burocráticos de órgãos ligados às esferas federais e municipais. O caso do Orçamento Participativo é ilustrativo: esse processo que em seu início tinha o poder de questionar a forma de produção de cidade de maneira abrangente, hoje resume-se a um processo pseudoparticipativo, onde a população apenas escolhe (com muitas limitações) qual empresa terá o direito de executar as obras.

Observa-se, portanto, no caso do Orçamento Participativo a capacidade de cooptação dos instrumentos de participação genuinamente populares por meio de atores ligados ao grande capital imobiliário em conluio com a gestão municipal. Os "desvios de percurso" nas propostas iniciais do Orçamento Participativo sugerem explicitamente o reconhecimento das políticas de gestão habitacional no município de Porto Alegre como verticalizadas e prioritariamente voltadas para o lucro imobiliário.

Dentre as experiências de participação criadas a partir dos tensionamentos produzidos pelos movimentos sociais pelo direito à moradia e a cidade, destaca-se o Conselho Municipal de Acesso à Terra e Habitação (COMATHAB), que foi criado pela lei $337 / 1995$ e que, ao instituí-lo, deu-lhe poderes que poderiam realmente causar mudanças profundas na maneira que a habitação é pensada na cidade.

Desde que no Brasil, foi adotada uma postura de financeirizar os mais diversos setores serviço à cidadania, uma consequência direta dos esforços do capital internacional aliado à burguesia nacional, de implantar o neoliberalismo como guia dos governos e gestões públicas, à participação popular foi diminuída, enfraquecida, como estratégia para evitar a quebra desse processo. Conselhos e iniciativas de lei como a lei 337/95, romperiam esse processo violento de distribuição desigual da cidade. Como citado na proposição desta pesquisa no parágrafo das atribuições do COMATHAB, que é usado neste trabalho como exemplo de caso emblemático, destaca-se o seguinte parágrafo: 


\section{III - Propor o plano de aplicação e fiscalizar o gerenciamento do Banco de Terras}

O Banco de Terras do município de Porto Alegre que, primeiramente deveria ser utilizado para a direta promoção de unidades habitacionais é, hoje um instrumento de barganha entre Prefeitura e poder privado; criado para o interesse social, desvirtuou-se ao longo do tempo e agora serve como depositário de terra para o grande capital do setor imobiliário da cidade. Um dos exemplos emblemáticos desse esquema é a venda de boa parte dos prédios municipais localizados no centro da cidade de Porto Alegre (PMPA, 2016).

Conceber um conselho formado por pessoas escolhidas democraticamente e que viessem de um processo de luta por moradia e por uma cidade inclusiva, onde iriam gerir o Banco de Terras do município, do qual também faz parte os vazios urbanos de Porto Alegre, seria autorizar que o modelo de produção capitalista da cidade fique sob ameaça de se tornar um modelo democrático de gestão da cidade, começando pelos vazios e expandindose para outras áreas do tecido urbano. Uma evidência disso é que dentro das atribuições e poderes do COMATHAB está também a criação de comitivas de análise e criação de redes entre diferentes conselhos, que possam também pensar a cidade, como o Conselho do Plano Diretor e a Comitiva de Trânsito, importantes órgãos de observação, regulação e controle.

Além de poder gerir o Banco de Terras do município de Porto Alegre, é atribuição direta do COMATHAB gerir: os recursos do Fundo Municipal de Desenvolvimento - FMD, que hoje tem o nome de Fundo Municipal de Habitação de Interesse Social - FMHIS criado em 2009, depois da criação do Plano Nacional de Habitação - PlanHab (substituído em sua totalidade pelo Programa Minha Casa Minha Vida). Como compete ao Conselho Municipal de Acesso à Terra e Habitação a gerência destes recursos, os mais interessados teriam o poder de decidir onde e como morar. Unindo a gestão do Banco de Terras, com a gestão do FMHIS ter-se-ia dois importantes instrumentos, um que questionaria os vazios urbanos e outro que poderia preencher esses vazios urbanos, não mais uma política centralizada e distante da população, mas impregnada de autonomia deliberativa da sociedade civil.

Ao reconhecer a potencialidade deste conselho aqui apresentado como exemplo ilustrativo, reconhece-se também o seu poder transformador na cidade. Não mais levando a população menos favorecida economicamente para longe do centro urbano, mas sim, dando habitação e qualidade de vida, inserindo-a no centro da cidade. Uma nova maneira de pensar a gestão e o desenvolvimento urbano com mais humanidade e capacidade transformadora. 
O Conselho Municipal de Acesso à Terra e Habitação - COMATHAB, infelizmente não passa de uma lei que deveria estar em vigor. Quando da análise de todos os artigos desta lei, cotejados com outros importantes dispositivos como o Orçamento Participativo - OP e o Programa Minha Casa Minha Vida Entidade - PMCMV - E, chega-se a conclusão de que que a sua implantação, como citado acima, coloca em risco todo o modelo neoliberal de produção de cidade e todos os esforços que o grande capital nacional e internacional para a implantação em larga escala de modelos não participativos e desiguais de produção urbana, justamente pelo seu caráter contestador e capacidade de gestão democrática, seria um novo marco para o pensamento urbanístico no sul do Brasil.

O Fundo Municipal de Habitação de Interesse Social, sendo um fundo depositário de recursos do poder executivo tem como fonte muitas rendas oriundas de transações imobiliárias e aprovações de projetos arquitetônicos na cidade. Segundo a lei de criação do Fundo Municipal de Habitação de Interesse Social, o valor arrecadado com as taxas de aprovação de projetos em Porto Alegre seriam depositadas neste fundo bem como todo o valor arrecadado com a compra de índices, como está descrito na lei $n^{\circ} 612 / 2009$ :

Art. $2^{\circ}$ Os recursos do FMHIS são constituídos por:

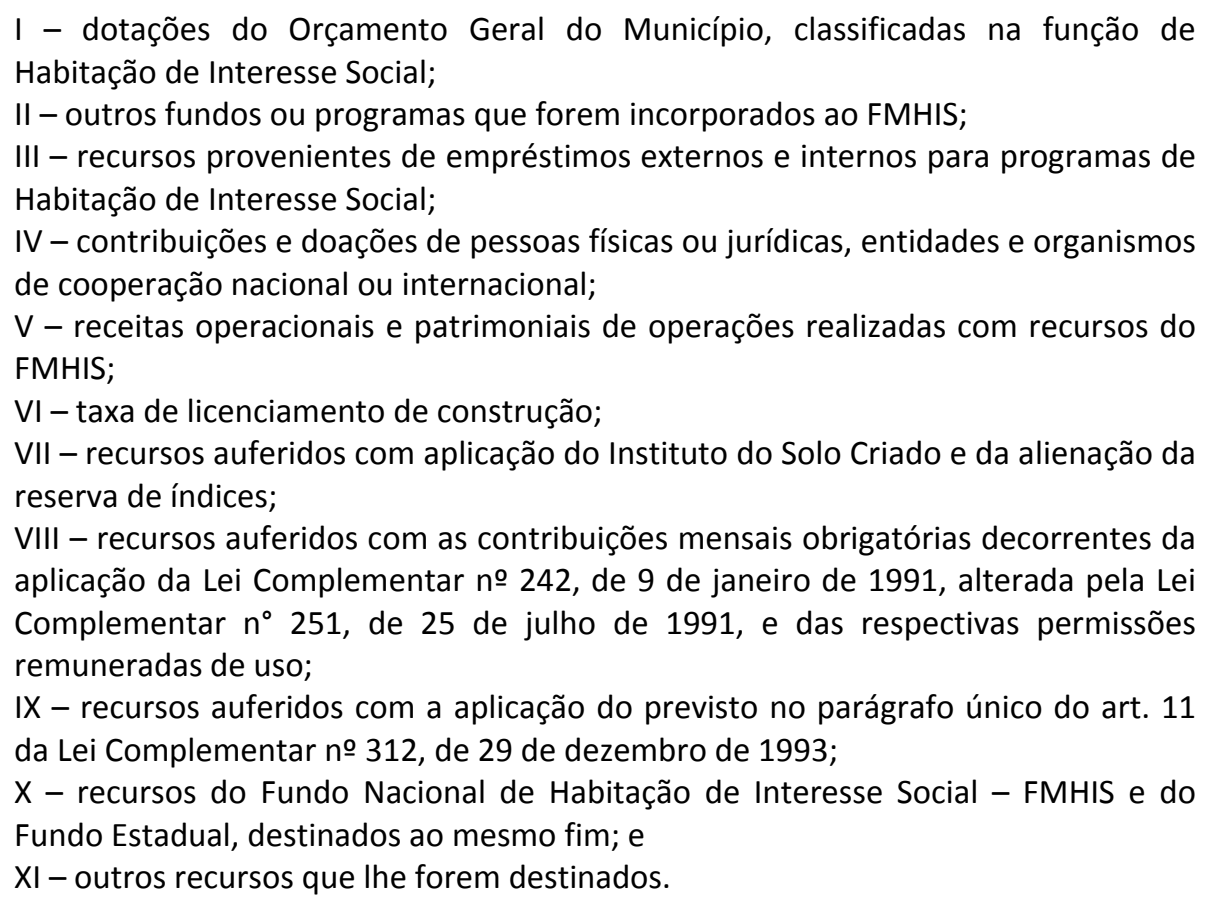

O Fundo Municipal de Habitação de Interesse Social, além de receber todas essas verbas oriundas do executivo municipal, ainda tem como seu conselho gestor nove conselheiros, dentre estes, seis conselheiros indicados pelo Conselho Municipal de Acesso à 
Terra e Habitação - COMATHAB, os outros três representantes governamentais serão indicados pelo Departamento Municipal de Habitação de Interesse Social - DEMHAB sendo que a presidência do FMHIS será exercida pelo Diretor-Geral do DEMHAB. O núcleo gestor deste fundo é, por essência, democrático, obedece à voz e aos interesses do povo.

Todavia, mesmo com todos esses dispositivos legais que asseguram ao funcionamento do FMHIS, ele em nenhum momento recebeu por completo todas as verbas que deveria receber, ainda, a partir da ascensão do Programa Minha Casa Minha Vida, o FMHIS perdeu completamente a sua força e passou a financiar apenas os valores ínfimos de aluguel social e de bônus moradia, outros programas paliativos do DEMHAB em Porto Alegre.

Ao ler as leis de criação de ambos dispositivos de cunho democrático, nota-se a íntima relação de funcionamento entre eles, o Fundo Municipal de Habitação de Interesse Social possui os recursos, o Conselho Municipal de Acesso à Terra e Habitação detém a gerência e a responsabilidade de guiar ao uso destes recursos. No entanto, é evidente a incipiente vontade política de por meio de programas transparentes, democráticos e comprovadamente viáveis economicamente resolver problemas ligados à área de Habitação de Interesse Social sem a nefasta participação de agentes ligados ao mercado imobiliário.

\section{Considerações Finais}

Está claro como a luz do sol que o Estado atual não pode nem quer remediar o flagelo da falta de moradias. O Estado nada mais é que a totalidade do poder organizado das classes possuidoras, dos proprietários de terras e dos capitalistas em confronto com as classes espoliadas, os agricultores e os trabalhadores. O que não querem os capitalistas individuais tampouco quer o seu Estado. Portanto, embora individualmente o capitalista lamente a escassez de moradia, dificilmente mexerá um dedo para dissimular mesmo que superficialmente suas consequências mais terríveis, o capitalista global, o Estado, também não fará mais do que isso. Quando muito, tomará providências para que o grau de dissimulação superficial que se tornou usual seja aplicado em toda parte do mesmo modo. Vimos que é exatamente isso que ocorre" Friedrich Engels.

Conforme visto ao longo desta investigação a questão da moradia transcende em muito com o aspecto quantitativo para aliar-se à dimensão que diz respeito ao direito a cidade. Sem menosprezar alguns ganhos quantitativos pode-se afirmar que o Programa 
Minha Casa Minha Vida, ao centralizar os recursos federais, acabou por inibir diversas iniciativas locais de grande representatividade e maior radicalidade no sentido de proporcionar o acesso para a cidade e às camadas menos favorecidas da população. Deve-se ressaltar ainda, que o programa Minha Casa Minha Vida tem origem no período populista dos governos federais no Brasil, no ano de 2009 e teve como ponto de partida uma aliança explícita entre os grandes empresários da construção civil com o governo federal. Sua implementação contou com a participação ínfima da sociedade civil, fato este que ocasionou que os grandes beneficiários, que colheram os resultados financeiros da sua gestão foram as grandes empreiteiras e os governos que utilizaram de forma propagandista os seus resultados baseados exclusivamente em aspectos quantitativos em detrimento aos parâmetros qualitativos.

Faz-se necessário denunciar que o Programa Minha Casa Minha Vida, para além de algum significado positivo quanto, ao aspecto da propalada falta de moradia nas cidades, caracterizou-se como um explícito programa de transferência de capital do Governo Federal e, portanto da população, para a iniciativa privada. Um dos fatores que esclarecem de forma contundente essa indispensável autocrítica é o percentual de recursos destinados ao Programa Minha Casa Minha Vida tradicional, 98,5\% enquanto que, apenas 1,5\% foi destinado ao Programa Minha Casa Minha Vida Entidades. Deve-se esclarecer que o Programa Minha Casa Minha Vida Tradicional era intermediado pelas grandes incorporadoras imobiliárias, ao passo que o Minha Casa Minha Vida Entidades tratava os recursos do Governo Federal, diretamente sob a forma de cooperativas, associações de moradores, entre outras. Os resultados alcançados pelo Programa Minha Casa Minha Vida Entidades, que teve recursos ínfimos se comparados ao Programa Minha Casa Minha Vida tradicional, foram significativamente superiores no que diz respeito à qualidade construtiva, projetual e inserção dos empreendimentos no tecido urbano.

Pode-se dizer ainda ao fazer uma análise crítica do Programa Minha Casa Minha Vida, que ao considerar-se os aspectos negativos de sua implementação destaca-se aquele que consiste no eixo do trabalho de investigação aqui proposto: O Programa Minha Casa Minha Vida esvaziou contundentemente outros programas ao nível local que apresentavam radicalidade no sentido de um progresso substancial no direito a cidade para as classes menos favorecidas da população.

Em especial foi tratado nesse trabalho sobre o Conselho Municipal de Acesso à Terra e Habitação (COMATHAB), que de acordo com os aspectos elencados anteriormente, 
caracteriza-se como um exemplo emblemático de gestão habitacional que passou por uma interdição em função da radicalidade das suas propostas nos sentido de promoção do direito a cidade para todos. Faz-se necessário encontrar a melhor maneira de reativar o COMATHAB ou um órgão semelhante que se vincule à regeneração do Orçamento Participativo, fazendo com que as obras de habitação em Porto Alegre sejam realmente escolhidas e geridas pelos seus futuros moradores.

Conclui-se, portanto, que a centralização de recursos no MCMV, também trouxe consigo um indesejável esvaziamento das políticas públicas municipais e da participação efetiva da população nos projetos de implementação de Habitação de Interesse Social em Porto Alegre. Esse quadro deve ser revertido por todos atores sociais que buscam criar um mais propício para a retomada da real participação da população interessada na decisão de onde e como morar e viver em uma CIDADE PARA TODOS.

Finalizando esta investigação, considerou-se que fica notória a efetiva e indispensável participação popular nos programas de gestão habitacional, para mesmo que primeiramente em termos reformistas, o direito a cidade seja assegurado à todas as camadas da população.

Cidade, é nesse contexto, luta de classes e a superação de sua produção e reprodução pelo modo capitalista vigente insere-se, inexoravelmente, em uma transformação abrangente no sentido de um concreta emancipação social e humana.

\section{Referências}

ALFONSIN, B. M. Política habitacional em Porto Alegre: cinco eixos estratégicos. Porto Alegre, Sul21, 2012.

ALFONSIN, J. T. Das legalidades injustas às ilegalidades justas. Ed. Armazém Digital. 2013.

BONDUKI, N. Origens da habitação social no Brasil. 3. Ed. São Paulo: Libertadora, 2002.

CAMPOS, D. P. T.; TABBAL, L. M.; CARPENEDO, S. M. O departamento municipal de habitação e seus programas para a promoção da moradia social em Porto Alegre. Porto Alegre:

Sustentabilidade e Habitação de interesse Social. CHIS 2014, 2014

IBGE. Censo 2000. Disponível em: www.ibge.gov.br. Acesso em 5 des. 2016.

IBGE. Censo 2000. Disponível em: www.ibge.gov.br. Acesso em: 5 dez. 2016.

DEMHAB - DEPARTAMENTO MUNICIPAL DE HABITAÇÃO. PMHIS - Plano Municipal de Habitação de Interesse Social. Porto Alegre: DEMHAB, 2008. 
DEMHAB - DEPARTAMENTO MUNICIPAL DE HABITAÇÃO. Departamento Municipal de Habitação. Porto Alegre: DEMHAB, 2015.

ENGELS, F. Sobre a questão da moradia. Tradução de Nélio Schneider. São Paulo. Boitempo, 2015.

FEDOZZI, Luciano. Orçamento Participativo: reflexões sobre a experiência de Porto Alegre. Porto Alegre: Tomo Editorial, 1997.

PORTO ALEGRE. Prefeitura Municipal. Prefeitura inicia venda de imóveis municipais.

Disponível em:

<http://www2.portoalegre.rs.gov.br/smf/default.php?p_noticia=185839\&PREFEITURA+INICI +VENDA+DE+IMOVEIS+MUNICIPAIS>Acesso em: 10 fev. 2018.

PORTO ALEGRE. Prefeitura Municipal. Habitação é prioridade em Porto Alegre. 2009.

Disponível em: <http://www2.portoalegre.rs.gov.br/demhab

/default.php?reg=1\&p_secao=98>. Acesso em: 13 dez. 2016.

PORTO ALEGRE. Lei n 337, de 10 de janeiro de 1995.

PORTO ALEGRE. Lei $\mathrm{n}^{\circ}$ 612, de 19 de fevereiro de 2009.

ROLNIK, R. Guerra dos lugares: a colonização da terra e da moradia na era das finanças. 1. ed. São Paulo. Boitempo, 2015.

SCHIMIDT, C.; LAY, M. C. D.; OLIVEIRA, C. E. H. Produção da habitação social em Porto Alegre: adequação espacial e estratégias de geração de trabalho e renda. In: SALÃO DE INICIAÇÃO CIENTÍFICA, 28, 2006, Porto Alegre. Anais...Porto Alegre: UFRGS, 2006. 
Recebido em: 18/12/2017

Aceito em: 22/01/2018 